\title{
ECOLOGICAL NICHE MODELLING OF HIMALAYAN LANGUR (Semnopithecus entellus) IN SOUTHERN FLANK OF THE HIMALAYA
}

\author{
Laxman Khanal $^{1,2}$, Mukesh Kumar Chalise ${ }^{1^{*}}$, Xuelong Jiang ${ }^{2 *}$ \\ ${ }^{1}$ Central Department of Zoology, Institute of Science and Technology, Tribhuvan University, Kathmandu, Nepal \\ ${ }^{2}$ Kunming Institute of Zoology, Chinese Academy of Sciences, Yunnan, China \\ *Corresponding authors: mkchalise@cdztu.edu.np; jiangxl@mail.kiz.ac.cn
}

(Received: September 18, 2018; Revised: October 8, 2018; Accepted: October 12, 2018)

\begin{abstract}
The species and subspecies status of various populations of the Himalayan langur (Semnopithecus entellus) have been disputed in many literatures. Before delineating the taxonomic boundaries, it is important to identify the potential distribution areas of extant populations of the species. Ecological niche modeling (ENM) can be coupled with the systematic survey of species presence to identify the species' potential distribution range. Therefore, we did extensive survey and population census of the Himalayan langur across three major river basins (Koshi, Gandaki and Karnali) of Nepal and analyzed the population patterns. In addition, we also modelled the ecological niche of the species by using maximum entropy (MaxEnt) algorithm. We counted a total of 559 individuals from 33 troops that accounted the average troop size of $16.94( \pm 8.39)$ individuals. Within Nepal territory, the highest population of langurs was observed from the Gandaki River basin followed by the Karnali River basin. We revealed that Himalayan langurs have a wide range of altitudinal (49 m - $4190 \mathrm{~m}$ above sea level) distributions from Bhutan to Kashmir across southern flank of the Himalaya. We warrant for the detail distribution assessment and taxonomic analysis of Himalayan langurs using ecological, morphological and genetic variables.
\end{abstract}

Keywords: Colobines, Ecological niche, River basins, Nepal Himalaya, Population

\section{INTRODUCTION}

Colobine monkeys are distributed in sub-Saharan African forests and all over the South and Southeast Asia (Fashing 2007). The extant colobine species belong to 10 genera in two subtribes- the African Colobina and the Asian Presbytina. The later includes seven genera, namely Pygathrix, Rhinopithecus, Nasalis, Simias, Presbytis, Trachypithecus and Semnopithecus (Wang et al. 2013). The evidences obtained from the fossil records support the divergence between ancestral African colobines and Asian colobines occurred between 10 - 13 Mya (Delson 1992). The colobines have been described to have experienced recent and rapid adaptive divergence, in addition, they are more diverse and widespread for different climate environments (Wang et al. 2013).

Hanuman langurs are unique among the Asian colobines in terms of their wide distribution in a range of habitats (Roonwal \& Mohnot 1977). They are distributed throughout most parts of India and Sri Lanka, and are also found in some parts of Pakistan, most of the areas of Nepal, and some areas in Bangladesh (Karanth et al. 2010). The species and subspecies status of various populations of the Himalayan langurs (Semnopithecus entellus) have been disputed in many literatures (Karanth et al. 2010). Earlier, most authors considered the single species, S. entellus, of Hanuman langurs dividing the species up to 16 subspecies (Roonwal \& Mohnot 1977). More recently, the genus Semnopithecus has been divided into two (Brandon-Jones 2004), three (Karanth 2010), and even seven (Groves 2001) distinct species. Ashalakshmi et al. (2014) studied the phylogenetic relationship among the South-Indian populations of Semnopithecus and validated the species status of $S$. priam and $S$. hypoleucus described based on morphology. However, the taxonomic positions of the Himalayan langurs ( $S$. entellus) are yet to be tested by molecular analyses.

Before delineating the taxonomic boundaries, it is important to identify the potential distribution areas of the species, so that, the taxonomic study could use the samples from its all the extant populations. Determining the spatial distribution of a species is a multifaceted task (Boubli \& de Lima 2009). At present, availability of several mathematical techniques that are based on the concept of a species' fundamental ecological niche facilitates prediction of geographical distribution of a species (Mazel et al. 2017). The fundamental niche of a species comprises of a set of all necessary conditions that allow potential distribution and long-term survival, whereas its realized niche is a subset of the fundamental niche that is currently occupied as the realized distribution (Hutchinson 1957, Phillips et al. 2006). The species' realized niche is often smaller than its fundamental niche as it is under the influence of human activities; biotic interactions such as inter-specific competition and predation; or geophysical barriers that hinder their dispersal and colonization. Prevalence of such factors often prevent the species from inhabiting conditions encompassing its full ecological potential (Pulliam 2000). 
If the realized niche and fundamental niche of a species fully coincide with each other, the modeling algorithm can characterize the species' full fundamental niche (Warren et al. 2008). A niche-based model predicts the suitability in an ecological space, that in turn is projected into geographic space, yielding a geographic area of potential presence for the species (Phillips et al. 2006). Ecological niche models identify consistent differentiation patterns in characters related to the ecological niche and might provide alternative means of recognizing putatively independent lineages and thus act as an effective tool in delimiting species boundaries (Ortiz-Martinez et al. 2008).

Ecological niche modeling (ENM) can be coupled with the systematic survey of species presence to identify the species' potential distribution range (Ortega-Huerta \& Peterson 2008) relating the field observations to environmental layers of predictor variables (Guisan \& Thuiller 2005). ENMs are useful in one of four ways-i) to estimate the species niche, ii) to estimate the relative suitability of currently distributed areas of the species, iii) to estimate the relative suitability of potential habitat in geographic areas yet to be discovered for occurrence of the species, and iv) to estimate changes in the suitability of habitat over time under a specific scenario for environmental change (Warren \& Seifert 2011). The popularity of ENM tools have been increased for predicting the geographic ranges of species and have made important contribution for conservation (Kremen et al. 2008), for predicting changes in distribution from past or future climatic events (Hijmans \& Graham 2006), and for investigating patterns of speciation and niche divergence (Warren et al. 2008).

The ENM offers multiple benefits over the traditional mapping techniques by producing a more accurate and robust map even with an incomplete and noisy dataset (Acharya et al. 2018). ENMs establish relationships of known species occurrences with potential environmental covariates, then predict spatial and temporal distribution of the species. MaxEnt, Boosted Regression Tree (BRT), Tree Net and Random Forest are some of the widely used machine learning ENM algorithms (Acharya et al. 2018, Merow et al. 2013). Among the ENM techniques available at present, maximum entropy method or MaxEnt (Phillips et al. 2004) is designed to depict the distribution of individual species using presence-only data (Phillips et al. 2006). It outperforms other existing predictive methods (Elith et al. 2006) and has exponential growth in its application since introduction in 2004 (Morales et al. 2017).

Because of the limited studies on non-human primates in South Asia, the spatial extent of the Himalayan langur distribution is poorly known. Therefore, we aimed to unleash the ecological niche of the species and project that to the potential distribution in the southern flank of the Himalaya. By extensive surveys along the tributaries of major three river systems of Nepal, we assessed the population status of Himalayan langurs and collected geographical points of the species occurrence. We used species occurrence data and bioclimatic variables to model the ecological niche of the species employing maximum entropy (MaxEnt) algorithm.

\section{MATERIALS AND METHODS}

\section{Study area and research animal}

Nepal stands on latitude between $26^{\circ} 21^{\prime}$ to $30^{\circ} 27^{\prime}$ North and longitude between $80^{\circ} 4^{\prime}$ to $88^{\circ} 12^{\prime}$ East (Sharma 1999). It is roughly rectangular and slightly slanted towards the lower latitudes in the east. It extends about 800 kilometers along its east-west Himalayan axis and the width varies between 150 and 250 kilometers covering the total area of 147,181 square kilometers. The Nepal Himalaya forms the central one-third of the entire Himalayan range and includes multiple bioclimatic zones. It has geographic diversity ranging from 60 metres elevation in the tropical Tarai, beyond the perpetual snow line to over 7,000 metres including Earth's highest 8,848 meters (Mount Everest).

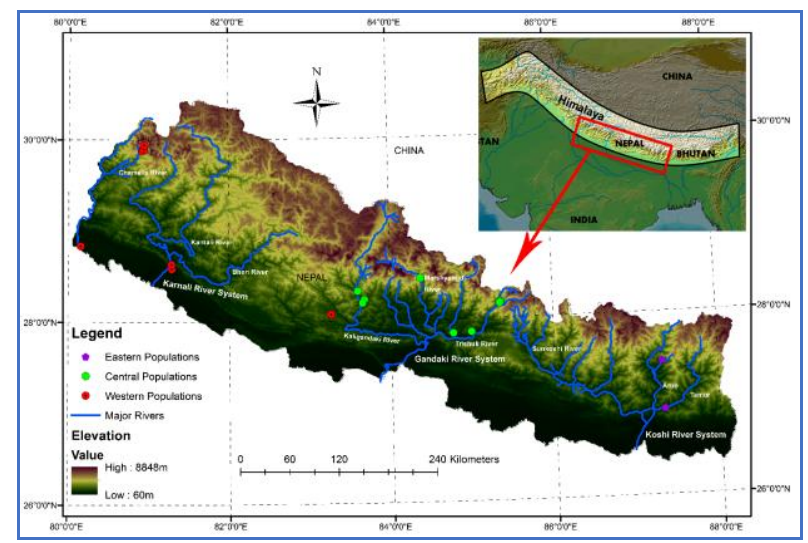

Fig. 1. Map of Nepal showing the elevational gradient and some occurrence points of Himalayan langur (Khanal et al. 2018b)

Surveys were conducted in three physiographic zones (Tarai, mid hills and lower Himalaya) across the three major River systems of Nepal- Koshi River System (KRS) on the eastern Nepal, Gandaki River System (GRS) on the central Nepal and Karnali- Mahakali River System (KMRS) on the western Nepal. Surveys were conducted in Tarai, Siwalik zone, mid hill zones and lesser Himalaya of the catchment areas of the three river systems (Fig. 1). It included some parts of eight protected areas of Nepal and non-protected Himalayan langur habitats in the mid hills.

Himalayan langurs are widely distributed from low-land Tarai to lower Himalayas. Chalise et al. (2005) suspected three subspecies of Himalayan langur in Nepal, with different IUCN red list status- Semnopithecus entellus hector (lesser hill langur) as critically endangered, Semnopithecus entellus ajax (western Himalayan grey 
langur) as endangered and Semnopithecus entellus schistaceus (central Himalayan langur or Nepal grey langur) as near threatened. S. entellus ajax is reported from East Langtang and Melamchi area of central Nepal. S. entellus hector is described from Central to West Nepal in outer Tarai and S. entellus schistaceus is reported from south to north in Central Nepal (Chitwan, Kathmandu \& Langtang) and the S. entellus hector is the smallest in size among the three, with yellowish fur on their chest and abdomen. The medium sized among these three is $S$. entellus ajax with mixed yellowish gray chest and abdomen. S. entellus schistaceus is the largest among the three with whitish chest and abdomen (Chalise et al. 2005).

\section{Field survey and population census}

Field surveys were conducted along both the sides of river tributaries by modified line transect methods starting from less than $100 \mathrm{~m}$ above sea level (asl) continued up to 4000 $\mathrm{m}$ asl. Three tributaries from each river system- Tamor, Arun and Sunkoshi from KRS, Trishuli, Marshyangdi and Kaligandaki from GRS and Bheri, Karnali and Chamelia from KMRS were surveyed. A total of 48 line-transects of each roughly $2 \mathrm{~km}$ length were surveyed on each river system. Wherever the Himalayan langur troops were observed, the detail population censuses were conducted for the troops. The geographical location of the troop was noted using Garmin 64s GPS. The troop size and population composition were observed in detail from the observation distance varying from about 10 to $100 \mathrm{~m}$ aided with the binocular whenever necessary. The individuals were divided into four age groups, namelyadults (male and female), sub-adults, juveniles and infants following the method of Chalise (2003). The counting was repeated until the concurrent readings were obtained for total count and age groups.

\section{Population distribution analysis}

The male to female sex ratios were calculated among the adult and sub-adult age groups separately as the number of males out of 100 females. The infant to female ratio of the monkey was calculated by dividing total number of infants by total number of adult females in the troop. The average troop size was computed as the mean of number of individuals among the observed troops. The significant difference in troop size, sex ratio and infant to female ratio among the three river systems and four physiographic zones were tested statistically by $\chi^{2}$ - test.

$$
\begin{aligned}
& \text { Averagetroopsize }=\frac{\text { Total no.of individuabbserved }}{\text { Total no.of troop observed }} \\
& \text { Male } \text { female ratio }=\frac{\text { No. of males of that age group }}{\text { No.of females of same age group }}
\end{aligned}
$$

Infant $:$ female ratio $=\frac{\text { Total no.of infants }}{\text { Total no.of reproductivefemales age }}$ Ecological niche modeling

\section{Model development}

We used the maximum entropy (MaxEnt) (Phillips et al. 2006) modeling approach for ecological niche modeling of Himalayan langur using the MaxEnt v.3.4.1(Phillips et al. 2017). MaxEnt is a machine learning program that uses presence- only data to predict distributions based on the principle of maximum entropy (Acharya et al. 2018). The basic principle of the MaxEnt model is to estimate the potential distribution of a species by determining the distribution of the maximum entropy(i.e., closest to uniform), with constraints imposed by the observed spatial distributions of the species and the environmental conditions (Phillips et al. 2006).

For the ENM of Himalayan langur, 33 occurrence points were recorded during the field survey. MaxEnt can have robust prediction with smaller number of occurrence points also (Phillips et al. 2006) and hence 33 occurrence points which covered almost entire Nepal are enough to represent the study area. The bioclimatic variables (Table 1) were clipped to a region from $78^{\circ} \mathrm{E}$ to $92^{\circ} \mathrm{E}$ and from $24^{\circ} \mathrm{N}$ to $31^{\circ} \mathrm{N}$ and exported to ASCII format. Seven bioclimatic variables (Bio: 1, 3, 5, 11, 12, 15, 18) were selected after removing highly correlated $(\mathrm{r} \geq|0.8|)$ variables based on Pearson correlation test $(\mathrm{P}<0.05)$.

\section{Model validation and analyses}

Jackknife validation method was used for validation of the model (Pearson et al. 2006). The species presence data were randomly divided into $75 \%$ as the training dataset and $25 \%$ as the validation dataset. To account for uncertainty introduced by training and validation set splits, 25 replicated models based on the cross-validation method were generated (Otto-Bliesner et al. 2006). It was used the linear quadratic and hinge features and set the maximum number of background points to 1,000 in this study. The accuracy of the models was evaluated by using area under the curve (AUC) of the receiving operating curve (ROC).

The logistic outputs of habitat suitability were converted to the binary outputs of unsuitable and suitable habitats using the threshold of maximum training specificity and sensitivity (maxTSS $=0.3777$ ) as explained for the model generated employing presence-only data by Liu et al. (2013). Then, the altitudinal range of the suitable habitat was evaluated by overlaying binary outputs to the SRTM DEM (http://www.cgiar-csi.org/data/srtm-90m-digitalelevation-database-v4-1). The elevations of the suitable habitat pixels were extracted and their mean, maximum and minimum were computed. 
Table 1. Bioclimatic variables used in the construction of ENM for Himalayan langur

\begin{tabular}{|c|l|l|}
\hline S. No. & Variables & \multicolumn{1}{|c|}{ Description } \\
\hline $1^{*}$ & Bio1 & Annual mean temperature \\
\hline 2 & Bio2 & Mean diurnal range [mean of monthly (max temp-min temp)] \\
\hline $3^{*}$ & Bio3 & Isothermally (P2/P7) $(\times 100)$ \\
\hline 4 & Bio4 & Temperature seasonality (standard deviation $\times 100)$ \\
\hline $5 *$ & Bio5 & Max temperature of warmest month \\
\hline 6 & Bio6 & Min temperature of coldest month \\
\hline 7 & Bio7 & Temperature annual range (P5-P6) \\
\hline 8 & Bio8 & Mean temperature of wettest quarter \\
\hline 9 & Bio9 & Mean temperature of driest quarter \\
\hline 10 & Bio10 & Mean temperature of warmest quarter \\
\hline $11^{*}$ & Bio11 & Mean temperature of coldest quarter \\
\hline $12 *$ & Bio12 & Annual precipitation \\
\hline 13 & Bio13 & Precipitation of wettest month \\
\hline 14 & Bio14 & Precipitation of driest month \\
\hline $15 *$ & Bio15 & Precipitation seasonality (coefficient of variation) \\
\hline 16 & Bio16 & Precipitation of wettest quarter \\
\hline 17 & Bio17 & Precipitation of driest quarter \\
\hline $18^{*}$ & Bio18 & Precipitation of warmest quarter \\
\hline 19 & Bio19 & Precipitation of coldest quarter \\
\hline Variables in the bold letters were used for the ENM after multicollinearity test \\
\hline
\end{tabular}

\section{RESULTS}

A total of 559 individuals of Himalayan langur were counted from 33 troops during the field survey (Table 2). The troop size ranged between 3-39 individuals per troop. The overall average troop size was calculated to be 16.94 $( \pm 8.39)$.

\section{Age-sex composition}

The Himalayan langur population had 278 adults and 281 young individuals that accounted the adult to young ratio of 1: 1.01. The adult male to female sex ratio was computed to be $1: 1.99$. The adult to young ratio and adult male to female sex ratio varied among the river systems but there was no significant statistical difference in the variation (Adult sex ratio, $\chi^{2}=0.136$, $\mathrm{df}=2, P=0.934$; Adult to young ratio, $\chi^{2}=0.002, \mathrm{df}=2, \mathrm{P}=0.99$ ).

\section{River system and elevation wise distribution of Himalayan langur}

Highest number of troops and individuals were observed from GRS (12 troops and 233 individuals) in central Nepal followed by the KMRS (13 troops and 214 individuals), and KRS (8 troops and 112 individuals) (Table 3). The highest average troop size was computed from GRS (19.41 individuals per troop) and the least was recorded from KRS (14 individuals per troop), however, there was no significant difference in average troop size among three river systems $\left(\chi^{2}=0.884, \mathrm{df}=2, \mathrm{P}=0.64\right)$.

The populations were grouped into five groups (Table 4) based on the elevation of their observation. Highest percentage of population was recorded from the elevation range from 500 to $1500 \mathrm{~m}$ above sea level followed by < $500 \mathrm{~m}$ asl, whereas, least percentage of population were observed from the elevation range beyond $3500 \mathrm{~m}$ above sea level (Table 4). There was a significant difference in distribution of populations at various elevation ranges $\left(\chi^{2}\right.$ $=19.50, \mathrm{df}=4, P<0.01)$. The number of troops and the average troop size also varied with the elevation gradients, however there was no significant difference in average troop size among the elevation groups $\left(\chi^{2}=3.73, \mathrm{df}=4, P\right.$ $=0.44)$. A total of 334 individuals of 18 troops were recorded within protected areas and rest 225 individuals of 15 troops were from outside protected areas.

\section{Ecological niche model for Himalayan Langur}

The MaxEnt produced similar results on both the sampling strategies. The mean AUC of 25 cross validation multiplication run was 0.892 ( $\mathrm{SD}=0.088)$ (Fig. 2) suggesting the potential distribution of Himalayan langur fits well with our data. The annual precipitation (Bio12) had the highest contribution to the model (40.3\%), while, the contributions of precipitation seasonality (Bio15; 22.1 $\%$ ) and mean temperature of the coldest quarter (Bio11; $16.9 \%$ ) were moderate. The response curves revealed that Bio12 in the range of 1600-2100 mm, Bio15 between 95 115 and Bio11 between $50-150\left(5-15^{\circ} \mathrm{C}\right)$ were ideal to define suitable habitat of Himalayan langur. The results of Jackknife test (Fig. 3) also validated the importance of Bio12 (annual precipitation) in defining the suitable habitat of Himalayan langur. 
Table 0. Geographic positions and population census of Himalayan langur in Nepal (2016/17)

\begin{tabular}{|c|c|c|c|c|c|c|c|c|c|}
\hline \multirow[t]{2}{*}{ S. No. } & \multirow[t]{2}{*}{ Place } & \multicolumn{3}{|l|}{ Location } & \multicolumn{4}{|c|}{ Population } & \multirow[t]{2}{*}{ Rem. } \\
\hline & & Latitude & Longitude & ASL & $\mathrm{AM}^{*}$ & $\mathrm{AF}^{*}$ & Young & Total & \\
\hline 1 & Mulghat west & $26^{\circ} 56^{\prime} 07.21^{\prime \prime}$ & $87^{\circ} 19^{\prime} 56.14^{\prime \prime}$ & 280 & 3 & 7 & 14 & 24 & KRS \\
\hline 2 & Bishranti Temple & $26^{\circ} 55^{\prime} 50.99^{\prime \prime}$ & $87^{\circ} 19^{\prime} 28.78^{\prime \prime}$ & 270 & 3 & 0 & 0 & 3 & KRS \\
\hline 3 & Bumlingtar & $27^{\circ} 27^{\prime} 26.31^{\prime \prime}$ & $87^{\circ} 07^{\prime} 32.84^{\prime \prime}$ & 460 & 5 & 9 & 11 & 25 & KRS \\
\hline 4 & Dongma & $27^{\circ} 27^{\prime} 34.4^{\prime \prime}$ & $87^{\circ} 07^{\prime} 19.85^{\prime \prime}$ & 554 & 2 & 5 & 6 & 13 & KRS \\
\hline 5 & Tamku & $27^{\circ} 27^{\prime} 34.64^{\prime \prime}$ & $87^{\circ} 18^{\prime} 58.79^{\prime \prime}$ & 556 & 3 & 6 & 14 & 23 & KRS \\
\hline 6 & Chatara & $26^{\circ} 50^{\prime} 25.40^{\prime \prime}$ & $87^{\circ} 09^{\prime} 05.89^{\prime \prime}$ & 123 & 2 & 3 & 4 & 9 & KRS \\
\hline 7 & GCA office & $27^{\circ} 44^{\prime} 19.60^{\prime \prime}$ & $86^{\circ} 10^{\prime} 00.52^{\prime \prime}$ & 964 & 2 & 3 & 7 & 12 & KRS \\
\hline 8 & Bungy jump & $27^{\circ} 52^{\prime} 36.27^{\prime \prime}$ & $85^{\circ} 53^{\prime} 30.18^{\prime \prime}$ & 1227 & 1 & 2 & 0 & 3 & KRS \\
\hline 9 & Riverside, LNP & $28^{\circ} 09^{\prime} 55.99^{\prime \prime}$ & $85^{\circ} 25^{\prime} 58.35^{\prime \prime}$ & 2594 & 3 & 5 & 9 & 17 & GRS \\
\hline 10 & Rishing, LNP & $28^{\circ} 10^{\prime} 21.28^{\prime \prime}$ & $85^{\circ} 21^{\prime} 01.94^{\prime \prime}$ & 1950 & 5 & 11 & 23 & 39 & GRS \\
\hline 11 & Khanjim & $28^{\circ} 10^{\prime} 05.63^{\prime \prime}$ & $85^{\circ} 21^{\prime} 40.75^{\prime \prime}$ & 2508 & 4 & 7 & 13 & 24 & GRS \\
\hline 12 & Shyafrubesi & $28^{\circ} 09^{\prime} 35.82^{\prime \prime}$ & $85^{\circ} 20^{\prime} 53.77^{\prime \prime}$ & 1477 & 1 & 4 & 4 & 9 & GRS \\
\hline 13 & Khalte & $27^{\circ} 51^{\prime} 03.80^{\prime \prime}$ & $84^{\circ} 59^{\prime} 29.30^{\prime \prime}$ & 689 & 4 & 6 & 14 & 24 & GRS \\
\hline 14 & Baseri & $27^{\circ} 50^{\prime} 28.15^{\prime \prime}$ & $84^{\circ} 45^{\prime} 59.61^{\prime \prime}$ & 382 & 3 & 7 & 9 & 19 & GRS \\
\hline 15 & Saattale & $28^{\circ} 27^{\prime} 05.73^{\prime \prime}$ & $84^{\circ} 22^{\prime} 33.25^{\prime \prime}$ & 1533 & 5 & 9 & 18 & 32 & GRS \\
\hline 16 & Jagaat & $28^{\circ} 24^{\prime} 44.92^{\prime \prime}$ & $84^{\circ} 24^{\prime} 38.31^{\prime \prime}$ & 1400 & 4 & 9 & 11 & 24 & GRS \\
\hline 17 & Kushma & $28^{\circ} 13^{\prime} 37.42^{\prime \prime}$ & $83^{\circ} 40^{\prime} 26.34^{\prime \prime}$ & 877 & 3 & 6 & 5 & 14 & GRS \\
\hline 18 & Dhairing & $28^{\circ} 13^{\prime} 19.53^{\prime \prime}$ & $83^{\circ} 35^{\prime} 43.53^{\prime \prime}$ & 1080 & 1 & 3 & 3 & 7 & GRS \\
\hline 19 & Balewa & $28^{\circ} 11^{\prime} 30.56^{\prime \prime}$ & $83^{\circ} 39^{\prime} 07.74^{\prime \prime}$ & 685 & 4 & 7 & 10 & 21 & GRS \\
\hline 20 & Siddheswor Cave & $28^{\circ} 13^{\prime} 27.42^{\prime \prime}$ & $83^{\circ} 40^{\prime} 29.34^{\prime \prime}$ & 895 & 3 & 0 & 0 & 3 & GRS \\
\hline 21 & Reshunga & $28^{\circ} 04^{\prime} 24.54^{\prime \prime}$ & $83^{\circ} 15^{\prime} 42.14^{\prime \prime}$ & 1748 & 2 & 4 & 7 & 13 & GRS \\
\hline 22 & Banke & $28^{\circ} 35^{\prime} 09.47^{\prime \prime}$ & $81^{\circ} 17^{\prime} 06.51^{\prime \prime}$ & 225 & 2 & 5 & 5 & 12 & KMRS \\
\hline 23 & Chisapani & $28^{\circ} 37^{\prime} 59.05^{\prime \prime}$ & $81^{\circ} 16 ' 57.72^{\prime \prime}$ & 212 & 3 & 8 & 14 & 25 & KMRS \\
\hline 24 & Babai bridge & $28^{\circ} 44^{\prime} 57.42^{\prime \prime}$ & $81^{\circ} 22^{\prime} 38.77^{\prime \prime}$ & 251 & 2 & 5 & 6 & 13 & KMRS \\
\hline 25 & Dhab, Dailekh & $28^{\circ} 54^{\prime} 57.42^{\prime \prime}$ & $81^{\circ} 24^{\prime} 38.77^{\prime \prime}$ & 695 & 2 & 5 & 7 & 14 & KMRS \\
\hline 26 & Suklaphanta NP & $28^{\circ} 50^{\prime} 09.90^{\prime \prime}$ & $80^{\circ} 09^{\prime} 02.28^{\prime \prime}$ & 180 & 1 & 4 & 6 & 11 & KMRS \\
\hline 27 & Okhreni & $29^{\circ} 52^{\prime} 43.80^{\prime \prime}$ & $80^{\circ} 54^{\prime} 58.60^{\prime \prime}$ & 2513 & 3 & 8 & 13 & 24 & KMRS \\
\hline 28 & Dhaumula & $29^{\circ} 53^{\prime} 48.90^{\prime \prime}$ & $80^{\circ} 56^{\prime} 11.12^{\prime \prime}$ & 3328 & 3 & 5 & 4 & 12 & KMRS \\
\hline 29 & DhauloOdhar & $29^{\circ} 56^{\prime} 41.06^{\prime \prime}$ & $80^{\circ} 56^{\prime} 27.78^{\prime \prime}$ & 3798 & 3 & 7 & 11 & 21 & KMRS \\
\hline 30 & Simar falls & $29^{\circ} 53^{\prime} 87.00^{\prime \prime}$ & $80^{\circ} 56^{\prime} 25.40^{\prime \prime}$ & 2871 & 4 & 9 & 13 & 26 & KMRS \\
\hline 31 & Chamelia & $29^{\circ} 56^{\prime} 25.50^{\prime \prime}$ & $80^{\circ} 56^{\prime} 49.10^{\prime \prime}$ & 3466 & 3 & 7 & 6 & 16 & KMRS \\
\hline 32 & Khayokot & $29^{\circ} 51^{\prime} 38.60^{\prime \prime}$ & $80^{\circ} 53^{\prime} 89.20^{\prime \prime}$ & 2139 & 2 & 5 & 5 & 12 & KMRS \\
\hline 33 & Dharmghar & $29^{\circ} 48^{\prime} 39.20^{\prime \prime}$ & $80^{\circ} 51^{\prime} 11.60^{\prime \prime}$ & 1769 & 2 & 4 & 9 & 15 & KMRS \\
\hline \multicolumn{5}{|c|}{ Total } & 93 & 185 & 281 & 559 & \\
\hline
\end{tabular}

*AM-adult male, AF- adult female, ASL- above sea level

Table 3. The river system wise distribution of Himalayan langur population in Nepal

\begin{tabular}{|l|l|l|l|l|l|l|l|l|}
\hline S.No. & \multirow{2}{*}{ River System } & \multirow{2}{*}{$\begin{array}{c}\text { No. of } \\
\text { Troops }\end{array}$} & \multicolumn{4}{|c|}{ Population } & \multirow{2}{*}{$\begin{array}{c}\text { Average } \\
\text { Troop Size }\end{array}$} & $\begin{array}{l}\text { Population } \\
\text { Percentage }\end{array}$ \\
\cline { 4 - 7 } & & & $\mathrm{AM}^{*}$ & $\mathrm{AF}^{*}$ & Young & Total & \\
\hline $\mathbf{1}$ & KRS & 8 & 21 & 35 & 56 & 112 & 14 & 20.04 \\
\hline $\mathbf{2}$ & GRS & 12 & 40 & 74 & 119 & 233 & 19.41 & 41.68 \\
\hline $\mathbf{3}$ & KMRS & 13 & 32 & 76 & 106 & 214 & 16.46 & 38.28 \\
\hline
\end{tabular}

"AM- adult male, $A F$ - adult female

Table 4. The elevation wise distribution of Himalayan langur in Nepal

\begin{tabular}{|c|c|c|c|c|c|c|c|c|}
\hline \multirow[t]{2}{*}{ S. No. } & \multirow{2}{*}{$\begin{array}{c}\text { Elevation (m above } \\
\text { sea level) }\end{array}$} & \multirow{2}{*}{$\begin{array}{l}\text { No. of } \\
\text { Troops }\end{array}$} & \multicolumn{4}{|c|}{ Population } & \multirow{2}{*}{$\begin{array}{l}\text { Average } \\
\text { Troop Size }\end{array}$} & \multirow{2}{*}{$\begin{array}{l}\text { Population } \\
\text { Percentage }\end{array}$} \\
\hline & & & $\mathrm{AM}^{*}$ & $\mathrm{AF}^{*}$ & Young & Total & & \\
\hline 1 & $<500$ & 9 & 24 & 48 & 69 & 141 & 15.67 & 25.22 \\
\hline 2 & $500-1500$ & 12 & 30 & 56 & 81 & 167 & 13.91 & 29.87 \\
\hline 3 & $1501-2500$ & 5 & 16 & 33 & 62 & 111 & 22.2 & 19.86 \\
\hline 4 & $2501-3500$ & 6 & 20 & 41 & 58 & 119 & 19.83 & 21.29 \\
\hline 5 & $>3500$ & 1 & 3 & 7 & 11 & 21 & 21 & 3.76 \\
\hline
\end{tabular}

$*$ AM- adult male, $A F$ - adult female 


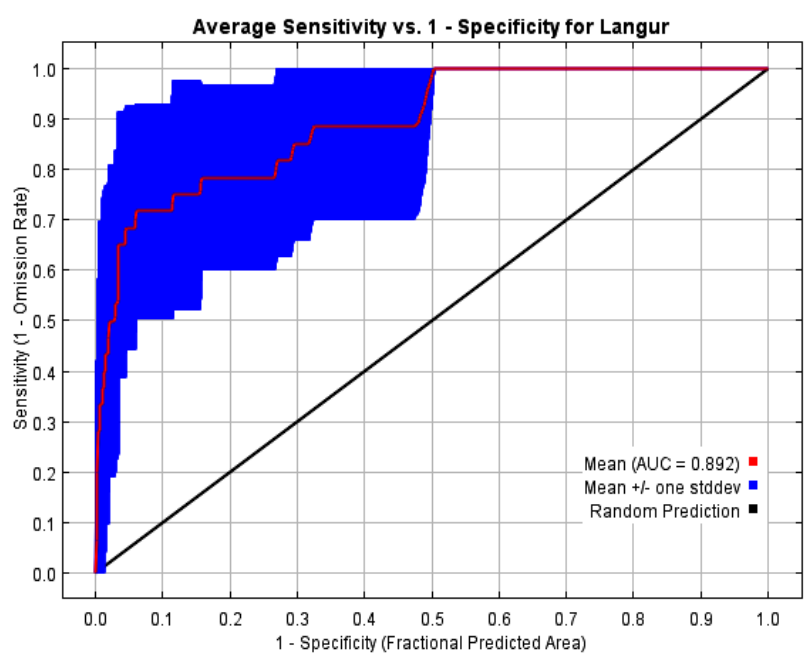

Fig. 2. Average area under curve (AUC) for 25 replicates of MaxEnt runs (red line is average value and blue bars represent \pm 1 standard deviation.

The potential habitat for Himalayan langur is widely distributed along the southern flank of the Himalaya from Bhutan in the east to Kashmir in the west (Fig. 4). Within
Nepal, it is mainly distributed at tropical lowland Tarai, subtropical mid-hills and temperate lower Himalaya of eastern and central region, and lowland Terai and midhills of western parts of the country. The elevation range of the current suitable habitat was found to be between 49 $\mathrm{m}$ to $4190 \mathrm{~m}$ above sea level with the mean value of 1823 $\mathrm{m}$ above sea level.

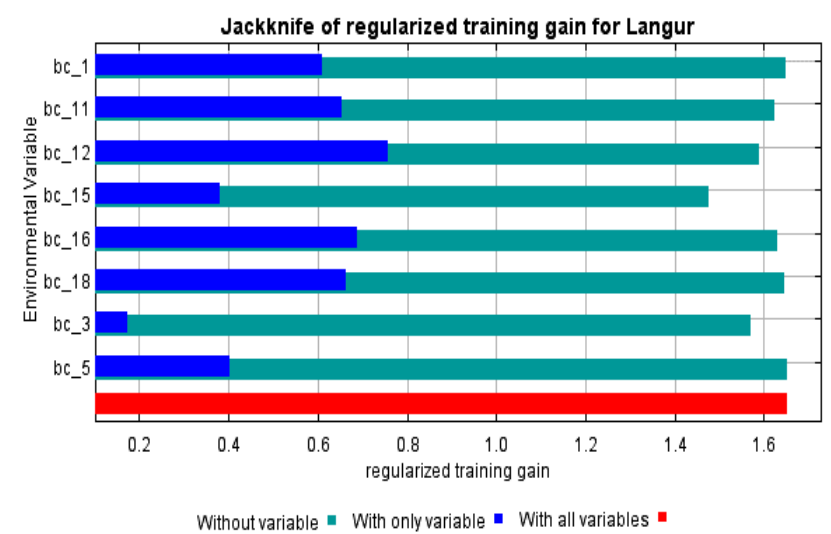

Fig. 3. Variable importance by Jackknife test for ENM of Himalayan langur. The blue, aqua and red bars represent the results with each variable, remaining all variables and all the variables, respectively.

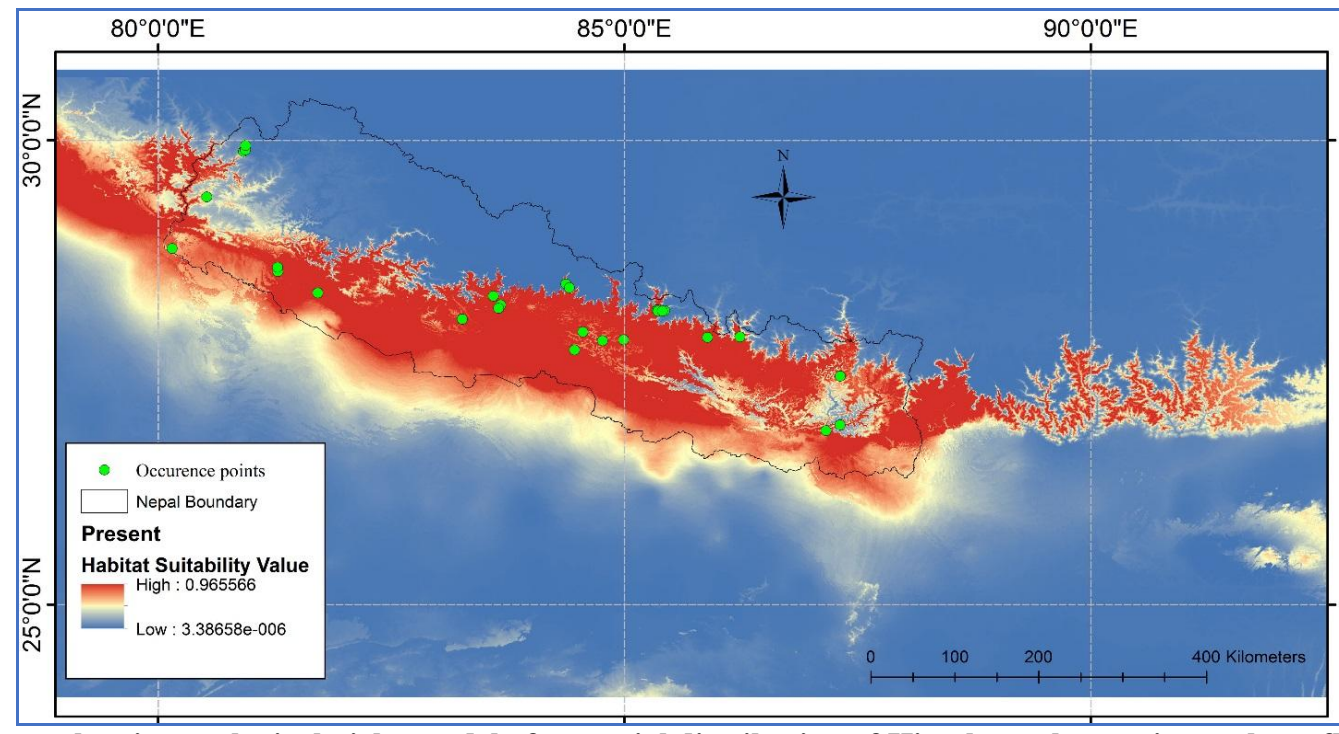

Fig. 4. The map showing ecological niche model of potential distribution of Himalayan langur in southern flank of Himalaya

\section{DISCUSSION}

Amongst the most widely distributed non-human primates in South Asia, Himalayan langur is a common sight in diverse natural habitats and tourist areas (Groves 2001). The distribution range of Himalayan langur in Nepal Himalaya is wider than that of Assam macaque, another species of non-human primate having synoptic distribution at many places (Khanal et al. 2018a, 2018b). They have been observed from lowland Tarai to lower Himalaya up to the elevation of about $4000 \mathrm{~m}$ above sea level. They are distributed along entire east-west length of
Nepal Himalaya and live everywhere in Nepal except in permanent snow (Chalise et al. 2005). The recent study on Himalayan langur counted 1,113 individuals from 67 troops in Nepal with average troop size of 16.61 individuals (Chalise 2013), but these observations were the accumulated results for the studies of last two decades.

The average troop size of the species (16.94) was found consistent with that of previous reports, 17 individuals per troop (Chalise 2008) in western Nepal and 16.61 individuals per troop in entire Nepal (Chalise 2013) During this study, the highest average troop size (22.2) 
was recorded for the elevation range of 1500-2500 m above sea level and the average troop size was higher for the populations within protected areas (PAs, 18.56) than those of outside the PAs (15.0). Highest number of Himalayan langur troops and individuals were recorded from GRS followed by KMRS in western Nepal, that differed with the distribution of Assam macaques which are more abundant in GRS and KRS in eastern Nepal (Khanal et al. 2018). Western Nepal is relatively drier than the eastern side receiving less precipitation from the summer monsoon. Dry tolerant nature of the Himalayan langur could acclimatize the species to the arid regions (Nag et al. 2014) of the western Nepal.

Himalayan langurs are "generalist folivores" and as such take advantage of seasonal products when available and occupy a wide variety of habitat types from arid regions on the edge of deserts to the rain forests (Bishop 1979, Nag et al. 2014). They inhabit subtropical to temperate broadleaved forests, pine forests, montane forests, riverine forests, rocky outcrops, and scrub jungles (Molur et al. 2003). They are adapted to the encroaching heat of Tarai, the harsh winter of mid-hills and chilly atmosphere by occasional snow at the lap of Himalaya (Chalise et al. 2005). Nag et al. (2014), by species distribution modeling, predicted the highest area of suitable habitats for $S$. entellus within Indian Territory among different species of langurs. The MaxEnt model during this study revealed that the suitable habitat for Himalayan langur is mainly determined by higher annual precipitation and moderate temperature of the coldest quarter of the year. Higher annual precipitation totaled from the South Asian summer monsoon and winter westerlies may support broadleaved vegetations favored by the folivores like Hanuman langur. The suitable habitat for Himalayan langur is widely distributed along the southern flank of the Himalaya from Bhutan in the east to Kashmir in the west. The paleodistribution reconstruction for Himalayan langur could not detect remarkable habitat loss and range shifts in LGM when compared to the present range (Khanal et al. $2018 b$ ). The projection of the current ecological niche of the species for future climate change scenario also didn't have statistically convincing model predictions (Khanal 2018).

Elevational range of Hanuman langur distribution is wide spanning from sea level to $4270 \mathrm{~m}$ above sea level in the Himalayas (Sayers \& Norconk 2008). The molecular data analyses and paleo-distribution reconstruction did reveal that Himalayan langurs have long evolutionary history in the central Himalaya and experienced some degree of elevational range shift towards lower elevations during the dry and cold period of the last glacial maximum (Khanal et al. 2018b). This study predicted the current altitudinal distribution of the species ranging between $49 \mathrm{~m}$ to 4190 $\mathrm{m}$ above sea level with the mean value of $1823 \mathrm{~m}$ above sea level. The annual precipitation in the Hanuman langur habitats range between $10 \mathrm{~cm}$ and $740 \mathrm{~cm}$ (Nag et al. 2014). Though they have wide range of tolerance on available moisture, the ENM in this study revealed that $1600-2100 \mathrm{~mm}$ annual precipitation is ideal to define the optimum habitat of the species. In addition to the wide altitudinal range, Himalayan langurs have a wide latitudinal range inhabiting the moist riverine forests of north-eastern India and eastern Nepal influenced by the summer monsoon as well as relatively dry areas of western Nepal, north-western India and Kashmir which are much influenced by westerlies. Such a wide range of latitudinal and altitudinal distribution of the species since long has created morphological variations and the populations are doubted for separate taxonomic categories. Therefore, it is necessary to elucidate the taxonomic ambiguities among Himalayan langur populations by employing morphological, behavioral and molecular data recovered from all the extant populations.

Our study used only the bioclimatic variables in defining the ecological niche of Himalayan langur which alone may not define the complete niche, therefore it should be cautiously weighed in the light of limitations of ENM. Use of other variables, viz., vegetation indices, hydrological layers, canopy density, habitat preference, feeding pattern, troop dynamics, and niche occupancy could define more precise ecological niche of the Himalayan langur (Nag et al. 2014). Future research should focus on employing multiple variables and a greater number of occurrence data (Khanal et al. 2018c). Additionally, taxonomic subdivisions of the Himalayan langur (S. entellus) populations into subspecies level and predictions of ecological niches of individual subspecies separately would be of great importance.

\section{CONCLUSION}

We conclude that Himalayan langur population in Nepal is distributed in a wide elevational and latitudinal range from tropical lowland Tarai to temperate lower Himalayas. The population is sporadically distributed at fragmented forest patches. The potential habitat of the species is widely distributed from Bhutan to Kashmir along the southern flank of the Himalaya. Further taxonomic subdivisions of the wide spread populations and respective ecological niche modeling would enlighten the detail distribution pattern of Himalayan langur.

\section{ACKNOWLEDGEMENT}

We thank the Department of National Parks and Wildlife Conservation, Ministry of Forest and Soil Conservation, Government of Nepal for the research permission. All the field assistants and local people are appreciated for their help and contributions.

\section{REFERENCES}

Acharya, B.K., Cao, C., Xu, M., Khanal, L., Naeem, S. and Pandit, S. 2018. Present and future of Dengue fever in Nepal: Mapping climatic suitability by ecological niche model. International Journal of 
Environmental Research and Public Health 15(2): 187-201.

Ashalakshmi, N.C., Nag, K.S.C. and Karanth, K.P. 2014. Molecules support morphology: Species status of South Indian populations of the widely distributed Hanuman langur. Conservation Genetics 16(1): 4358 .

Bishop, N.H. 1979. Himalayan langurs: temperate colobines. Journal of Human Evolution 8: 251-281.

Boubli, J.P. and de Lima, M.G. 2009. Modeling the geographical distribution and fundamental niches of Cacajao spp. and Chiropotes israelita in Northwestern Amazonia via a maximum entropy algorithm. International Journal of Primatology 30(2): 217-228.

Brandon-Jones, D. 2004. A taxonmic revision of the langurs and leaf monkeys (Primates: Colobinae) of South Asia. Zoos' Print Journal 19(8): 1552-1594.

Chalise, M.K. 2003. Assamese monkeys (Macaca assamensis) in Nepal. Primate Conservation 19: 99107.

Chalise, M.K. 2008. Primate census in Kathmandu and west parts of Nepal. Journal of natural History Museum, Tribhuvan University 23: 60-64.

Chalise, M.K. 2013. Fragmented primate population of Nepal. In: L. K. Marsh \& C. A. Chapman (Eds.). Primates in fragments: complexity and resilience, Springer Science+Business Media, New York, pp. 329-356.

Chalise, M.K., Karki, J.B. and Ghimire, M. K. 2005. Status in Nepal: non-human primates. In: Special issue on the occasion of $10^{\text {th }}$ Wildlife Week, 2062. Department of National Parks \& Wildlife Conservation, Kathmandu, Nepal.

Delson, E. 1992. Evolution of Old World monkeys. In: S. Jones, R. Martin and D. Pilbeam (Eds). The Cambridge Encyclopedia of Human Evolution, Cambridge University Press, Cambridge, pp. 217222.

Elith, J., Graham, C.H., Anderson, R.P., Dudık, M., Ferrier, S., Guisan, A. and Zimmermann, N.E. 2006. Novel methods improve prediction of species' distributions from occurrence data. Ecography 29: 129-156.

Fashing, P.J. 2007. Behavior, Ecology, and Conservation of Colobine Monkeys: An Introduction. International Journal of Primatology 28(3): 507511.

Groves, C.P. (2001). Primate taxonomy. Smithsonian Institution Press, Washington DC.
Guisan, A. and Thuiller, W. 2005. Predicting species distribution: offering more than simple habitat models. Ecology Letters 8(9): 993-1009.

Hijmans, R.J. and Graham, C.H. 2006. The ability of climate envelope models to predict the effect of climate change on species distributions. Global Change Biology 12(12): 2272-2281.

Hutchinson, G.E. 1957. Concluding remarks. In: Cold Spring Harbor Symposia on Quantitative Biology 22: 415-427.

Karanth, K.P. 2010. Molecular systematics and conservation of the langurs and leaf monkeys of South Asia. Journal of Genetics 89 (4): 393-399.

Karanth, K.P., Singh, L. and Stewart, C.B. 2010. Mitochondrial and nuclear markers suggest Hanuman langur (Primates: Colobinae) polyphyly: implications for their species status. Molecular Phylogenetics and Evolution 54(2): 627-633.

Khanal, L. 2018. Riverine barrier and climatic effects on phylogeography of central Himalayan sympatric primates- Assam Macaque (Macaca assamensis) and Langur (Semnopithecus entellus). Ph. D. Dissertation, Kunming Institute of Zoology, University of Chinese Academy of Sciences, Kunming, China.

Khanal, L., Chalise, M.K., He, K., Acharya, B.K., Kawamoto, Y. and Jiang, X. 2018a. Mitochondrial DNA analyses and ecological niche modeling reveal post-LGM expansion of the Assam macaque (Macaca assamensis) in the foothills of Nepal Himalaya. American Journal of Primatology 80(3): e22748.

Khanal, L., Chalise, M. K., Wan, T. and Jiang, X. 2018b. Riverine barrier effects on population genetic structure of the Hanuman langur (Semnopithecus entellus) in the Nepal Himalaya. BMC Evolutionary Biology 18(1). doi:10.1186/s12862-018-1280-4

Khanal, L., Chalise, M.K., Wan, T. and Jiang, X.L. 2018c. Himalayan rivers and Pleistocene climatic fluctuations influenced population genetic structure of the Hanuman Langur (Semnopithecus sp.). Paper presented at the Satellite International Symposium on Asian Primates-2018, Kathmandu.

Kremen, C., Cameron, A., Moilanen, A., Phillips, S.J., Thomas, C.D., Beentje, H. and Zjhra, M.L. 2008. Aligning conservation priorities across taxa in Madagascar with high-resolution planning tools. Science 320(5873): 222-226.

Liu, C., White, M. and Newell, G. 2013. Selecting thresholds for the prediction of species occurrence with presence-only data. Journal of Biogeography 40(4): 778-789. 
Mazel, F., Wuest, R.O., Gueguen, M., Renaud, J., Ficetola, G.F., Lavergne, S. and Thuiller, W. 2017. The geography of ecological niche evolution in mammals. Current Biology 27(9): 1369-1374.

Merow, C., Smith, M.J. and Silander, J.A. 2013. A practical guide to MaxEnt for modeling species' distributions: what it does, and why inputs and settings matter. Ecography 36(10): 1058-1069.

Molur, S., Brandon-Jones, D., Dittus, W., Eudey, A., Kumar, A., Singh, M. and Walker, S. 2003. Status of south Asian primates: conservation assessment and management plan (C.A.M.P.). Retrieved from Zoo Outreach Organisation /CBSG-South Asia, Coimbatore, India.

Morales, N.S., Fernandez, I.C. and Baca-Gonzalez, V. 2017. MaxEnt's parameter configuration and small samples: are we paying attention to recommendations? A systematic review. PeerJ 5: e3093.

Nag, C., Karanth, K.P. and Gururaja, K.V. 2014. Delineating ecological boundaries of Hanuman langur species complex in peninsular India using MaxEnt modelling approach. PLoS One 9(2): e87804.

Ortega-Huerta, M.A. and Peterson, A.T. 2008. Modeling ecological niches and predicting geographic distributions: a test of six presence-only methods. Revista Mexicana de Biodiversidad 79: 205-216.

Ortiz-Martinez, T., Rico-Gray, V. and Martinez-Meyer, E. 2008. Predicted and verified distributions of Ateles geoffroyi and Alouatta palliata in Oaxaca, Mexico. Primates 49(3): 186-194.

Otto-Bliesner, B.L., Marshall, S.J., Overpeck, J.T., Miller, G.H. and $\mathrm{Hu}$, A. 2006. Simulating Arctic climate warmth and icefield retreat in the last interglaciation. Science 311(5768): 1751-1753.

Pearson, R.G., Raxworthy, C.J., Nakamura, M. and Townsend Peterson, A. 2006. Predicting species distributions from small numbers of occurrence records: a test case using cryptic geckos in
Madagascar. Journal of Biogeography 34(1): 102 117.

Phillips, S.J., Anderson, R.P., Dudík, M., Schapire, R.E. and Blair, M.E. 2017. Opening the black box: an open-source release of Maxent. Ecography 40(7): 887-893.

Phillips, S.J., Anderson, R.P. and Schapire, R.E. 2006. Maximum entropy modeling of species geographic distributions. Ecological Modelling 190(3-4): 231259.

Phillips, S.J., Dudik, M. and Schapire, R.E. 2004. A maximum entropy approach to species distribution modeling. In: Proceedings of the Twenty-First International Conference on Machine Learning: 655-662.

Pulliam, H.R. 2000. On the relationship between niche and distribution. Ecology Letters 3: 349-361.

Roonwal, M.L. and Mohnot, S.M. 1977. Primates of south Asia: ecology, sociobiology and behavior. Harvard University Press, Cambridge, MA.

Sayers, K. and Norconk, M.A. 2008. Himalayan Semnopithecus entellus at Langtang National Park, Nepal: Diet, activity patterns, and resources. International Journal of Primatology 29(2): 509530.

Sharma, C.K. 1999. Physiography: Nepal nature's paradise: In: Majupuria, T. C. and Majupiria, R. K. (Eds.): Hari Devi, Gwalior, India. p. 4-8.

Wang, X., Zhang, Y. and Yu, L. 2013. Summary of phylogeny in subfamily Colobinae (Primate: Cercopithecidae) Chinese Science Bulletin 58(18): 2097-2103.

Warren, D.L., Glor, R.E. and Turelli, M. 2008 Environmental niche equivalency versus conservatism: Quantitative approaches to niche evolution. Evolution 62(11): 2868-2883.

Warren, D.L. and Seifert, S.N. 2011. Ecological niche modeling in Maxent: the importance of model complexity and the performance of model selection criteria. Ecological Applications 21(2): 335-342. 